\title{
Means of optimal body mass control and obesity prophylaxis among students
}

\author{
Osipov A.Yu. ${ }^{1,4}$, Kudryavtsev M.D. ${ }^{1,2,5}$, Gruzinky V.I. ${ }^{1}$, Kramida I.E. ${ }^{2}$, Iermakov S.S. ${ }^{3}$ \\ ${ }^{1}$ Siberian Federal University, Russia \\ ${ }^{2}$ Siberian State Aerospace University, Russia \\ ${ }^{3}$ Belgorod National Research University, Russia \\ ${ }^{4}$ Professor V.F. Voino-Yasenetsky Krasnoyarsk State Medical University, Russia \\ ${ }^{5}$ Krasnoyarsk State Pedagogical University of V.P. Astafyev, Russia
}

\begin{abstract}
Purpose:

approaches to control over limits of students body mass range and obesity prophylaxis through their physical condition improvement are offered.

Material: $\quad$ in the research 100 boy students, divided into 2 equal groups (experimental and control) participated. Their age was - 19-20 years. In the research we used methodic of control over maximal admissible body mass. Strength was registered by quantity of chin ups. Endurance was assessed by time of 3000 meters' distance run. Quickness was assessed by time of 100 meters' distance run. Besides, we considered the quantity of missed physical culture lessons.

Results: $\quad$ it was found that for successful body weigh reduction students have to significantly increase everyday motor functioning. It was also found that insignificant quantity of missed physical culture lessons can not noticeably influence on students physical condition. At the end of the researches tests showed some increment of strength and quickness and confident increase of endurance in experimental group students.

Conclusions: implementation of compulsory body mass control methodic in students' physical education will facilitated overcoming global threats for youth's health: obesity and immobile way of life.

Keywords: health, motor functioning, students, body mass, obesity prophylaxis, physical culture.
\end{abstract}

\section{Introduction}

At present time significant progressing of young people's obesity is registered throughout the world. It results from deficit of modern youth's everyday physical activity. Immobile way of life and obesity growth in different age groups is rather serious problem in many developed countries [16]. Reduction of such negative tendency requires intensive efforts of medical workers, pedagogues and specialists in physical education [3]. Researches show that modern young people spend most of their time with computer instead of gyms [30, 32, 49]. Durable sitting at computer monitor results in sleep worsening, day fatigue and absence of steady motivation for active functioning during day. Excessive work with computer results in obesity and diseases of muscular skeletal apparatus [33, 49]. In modern health protection system there are two equal aims: increase of population's physical activity and reduction of time, spent at computer [13].

For medical workers the fact that physical functioning is effective, accessible and cheap mean of fighting different diseases has become evident long ago. Risk of diseases can be easily prevented by physical exercises' practicing [5, 24]. Warburton D. [51] points at direct linear connection between motor functioning and human physical health. Blair S. found significant reduction of cardio-vascular diseases, brain attacks, and cancer of colon risk as well as prolongation of life span. All these are facilitated by different motor functioning forms,

\footnotetext{
(C) Osipov A.Yu., Kudryavtsev M.D., Gruzinky V.I.,

Kramida I.E., Iermakov S.S., 2017

doi:10.15561/20755279.2017.0107
}

including cardio-respiratory fitness practicing [6]. Review of scientific works shows that scientists agree in determination of physical activity's leading role in health protection and improvement in all population strata [24, $27,31]$. However, it is necessary to admit that in modern scientific medium there are different views on ways of motor functioning intensification among students.

Some scientists offer to fight with students' excessive weight by means of special diets in students' eating in combination with physical culture and sports practicing [2]. In the opinion of L. Pescatello, reasonable combination of physical functioning and diets in students' everyday life will give more positive results, comparing with bare diets and uncontrolled sports practicing [42]. Grygiel-Górniak B. confirms that usual eating and physical activity influence health of modern young people [19]. Unfortunately only professional diet specialists can select correct rational eating for great number of young people. Their consultations are rather expensive for most of students. Staff structure of educational establishments does not stipulate such specialists. That is why it is very difficult for young people to organize correct balanced eating. Scientists note young people's uncontrolled and independent usage of different methodic for body mass reduction (diets, fasting, application of different medications), which are, sometimes, very dangerous for organism. In the opinion of B. Abalkhail, educational programs for youth shall contain information about correct and healthy eating, optimal body mass and dimensions, use of everyday physical activity, prophylaxis of clinical obesity [1]. In other works need in urgent use of educational preventive measures on formation of young 
people's health culture and handsome body is noted [8, 45].

Specialists know that negative after effects of immobility can be removed by highly intensive trainings [28]. In the opinion of Bogdanis G., for this purpose, additional researches for finding optimal parameters of long, highly intensive trainings are required [9]. The author notes that it is necessary to more attentively regard the problems of such trainings safety. It will permit to exclude over-fatigue for different age groups of population and for students. In other studies it was shown that intensive physical loads strengthen students' health and facilitate their academic progress [17, 34, 46]. In application of such trainings it should be remembered that there is deficit of operative, reliable and informative methodic for control and assessment of loads intensity at physical culture lessons [7, 25].

Scientific researches show that physical health and functional fitness of most of students are not optimal for this category of population [38, 39, 47]. Specialists attract attention to wide opportunities for health improvement of this age and social group. Plotnikoff $\mathrm{R}$. points that students are ideal targets for intervention of healthy life style values. The author thinks that most of time students are embraced by observation of different profiles medical workers; they have opportunity to use material base of health related resources (stadiums, swimming pools, simulators' halls); they are admitted to wide theoretical knowledge about health and ways of its strengthening [43]. It is even possible to create certain health medium on territory of educational establishments [36]. In L. Korn's opinion for students' health strengthening educational establishments shall use the following: accessible and healthy eating in canteens; practice great number of sport mass measures; apply effective screening systems. Besides, physical culture lessons shall be compulsory for young people to receive bachelor's degree [26]. King K. notes that when creating programs for increasing students' physical activity it is necessary to obligatory consider existing in students campuses conditions for sports and physical culture practicing [23]. The author thinks that one of serious problems in increasing students' physical activity is difficulty of objective comparison of different researches' results. Different specialists use in their works rather subjective indicators of young people's physical activity. In other work it is noted that fitness coaches and medical workers have different points of view on healthy life style values' implementation among students [12]. Substantial contradiction was found between declaration of constant affirmations about young people's healthy life style and absence of specially developed programs for physical culture classes. Kudryavtsev M. thinks that such programs shall be based on application of modern means of students' physical health improvement [29]. Such means can include cardio-power training, different martial arts, and fitness aerobic and so on. In other works successfulness of fitness training programs' application in students' physical education is proved [35, 40]. Some works show that students' physical activity programs shall be built on the base of power trainings [20, 21, 50]. However there are significant contradictions in scientific medium concerning this idea. In L. Judge's opinion, construction of programs for students' physical activity shall be on the base of aerobic exercises [22]. The author affirms that easy admittance to sport facilities is an important step for higher fitness indicators of students. It should be admitted that admittance to sport facilities and their condition are not at proper level. It should be also noted that there are only a few programs on students' physical activity propaganda and their effectiveness is insufficient. Foreign scientists also note rather modest effect of physical activity and sports propaganda among young people [4]. Daskapan A. notes that many young people have psychological, social and personal barriers, preventing from regular physical exercises' practicing [14].

In our research we did not use methodic of students' body mass index (BMI) determination. It is connected with the fact that such methodic are rather subjective in assessment of optimal body mass and requires serious additional tests [10, 15, 41, 44].

Analysis of literature data shows that there are many points of view on solution of problem of students' physical health worsening. Such researches are often inconsistent and contradictory. That is why it is offered to concentrate efforts on solution of immobile way of life problem among young people and obesity prophylaxis.

Hypothesis: the author assumed that solution of problem of young people's excessive weight and obesity would be facilitated by including one more criterion in list of compulsory physical culture control tests: range of optimal body mass of students. The author thinks that control over limits of students' weight categories will permit to substantially increase everyday motor functioning of young people and their physical health. Application of this methodic contains an element of scientific novelty: analysis of scientific literature did not show any works, devote to control over weight categories' limits in students.

The purpose of the research: is to improve students' physical condition and health; prophylaxis of obesity emersion and progressing in students at the cost of control over weight range limits of students’ body mass.

\section{Material and methods}

Participants: in the research 100 boy students, divided into 2 equal groups (experimental and control) participated. Their age was - 19-20 years. Selection of the participants was conducted, considering their body mass indicators. Weight range of all tested students was 78.4$84.5 \mathrm{~kg}$. Mean body mass of the tested was $82.3 \mathrm{~kg}$. All students - participants in the research gave their consent for participation in experiment.

Organization of the research: the researches took one academic year. For achievement of the set target experimental group students were offered to control body mass range during all experiment alongside with regular attendance of physical culture lessons. Maximal deviation 
from actual body mass was admitted in the range from 1 to $1.3 \mathrm{~kg}$. Control group students were not limited in control over their body mass. For them main condition was regular attendance of physical culture lessons. Before experiment at physical culture lessons all students were trained by traditional program. This program envisaged principles of main sport games' techniques (basketball, volleyball, football) and general physical training [48]. All students were offered to attend trainings by corrected physical education program during experiment. Specialists recommend to significantly intensifying young people's motor activity at the cost of aerobic physical exercises [4, 13, 16, 35]. Training program for the tested included: principles of hiking tourism and sport orientation; skiing; health related run; physical exercises for training main physical qualities. The main idea of the used exercises was increasing of movements' quantity of the tested.

In the course of experiment all students passed a number of tests for general physical fitness, which permitted to rather objectively assess their physical condition. Strength level was assessed by quantity of chin ups; endurance - by time of 3000 meters' distance run. Quickness was estimated by time of 100 meters' distance run. Besides, we considered total quantity of missed physical culture lessons.

Statistical analysis: was carried out with the help of SPSS20 program. Student's t-criterion was used for checking of mean values of two interconnected samples.

\section{Results}

Before experiment body mass indicators of experimental and control groups students were not confidently different. Weight range of control group students was 78.6 - $84.5 \mathrm{~kg}$. Mean body mass was 82.2 $\mathrm{kg}$. Weight range of experimental group students was $78.4-84.3 \mathrm{~kg}$, with mean body mass value $-82.4 \mathrm{~kg}$. At the end of experiment weight indicators of experimental and control groups students were confidently different. In control group body weight confidently $(\mathrm{p}<0.05)$ increased (in average from 82.2 to $85.7 \mathrm{~kg}$ ). Weight range of control group students was $82.4-88.6 \mathrm{~kg}$. In experimental group, mean body mass value insignificantly reduced, comparing with the beginning of experiment (from 82.4 to 81.1 $\mathrm{kg}$ ). Weight range of these students was $77.5-82.2 \mathrm{~kg}$. It should be noted that 7 students from experimental group exceeded admissible maximal-minimal deviations from body mass (5 persons exceeded maximum and 2 significantly reduced body mass). These students were excluded from further participation in the researches. But it did not influence significantly on results of the researches as far as quantity of the tested was rather big.

Results of control tests at the beginning of the researches sowed no confident prevalence of any physical quality in different groups. Students of experimental and control groups demonstrated approximately equal, rather moderate physical potential. At the end of the researches experimental group students confidently $(\mathrm{p}<0.05)$ increased their endurance and insignificantly increased strength and quickness. In control group we found confident $(p<0.05)$ reduction of quickness and endurance and insignificant reduction of strength indicators. These results are given in table 1.

\section{Discussion}

From results of our research it is evident that most students' everyday physical functioning and eating are not sufficient for maintaining optimal body mass. Control group students demonstrated significant (in average by $3.5 \mathrm{~kg}$ ) body mass increase during academic yeary. With it these students attended physical culture lessons regularly. The program of these lessons contained prevailing quantity of aerobic exercises. Many specialists recommend such exercises for prevention from immobility and obesity in young people [22, 35, 40, 42]. The quantity of missed lessons in average was составляет $3 \pm 3$ lessons in two semesters. Total quantity of physical culture lessons in

Table 1. Results of students' body mass studies

\begin{tabular}{lllll}
\hline & \multicolumn{2}{c}{ Before experiment } & After experiment \\
Physical qualities & Control group & $\begin{array}{l}\text { Experimental } \\
\text { group }\end{array}$ & Control group & $\begin{array}{c}\text { Experimental } \\
\text { group }\end{array}$ \\
\hline Strength (chin ups, quantity) & $10 \pm 4$ & $9 \pm 4$ & $9 \pm 3$ & $10 \pm 4$ \\
Quickness (100 meters' run, sec.) & $13 \pm 0.8$ & $14 \pm 0.2$ & $15 \pm 0.8^{*}$ & $13 \pm 0.6$ \\
Endurance (3000 meters' run, min.) & 13.26 & 13.41 & $14.48^{*}$ & $12.40^{*}$ \\
Body mass, kg & 82.2 & 82.4 & $85.7^{*}$ & $3 \pm 1.1$ \\
\hline
\end{tabular}

Notes: ${ }^{*}$ - p<0.05 - significance level. 
academic year is 36. Such quantity of missed lessons can not influence significantly on students' general physical fitness. Therefore for obesity prophylaxis in modern students only physical culture lessons are quite insufficient. Additional, regular and durable physical exercises' practicing in free time is required. Insufficient physical functioning negatively influenced of these students' physical condition. At the end of the research we found in them certain weakening of strength and significant reduction of quickness and endurance.

Most of experimental group students succeeded in keeping the set body mass parameters: only 7 persons (from $\mathrm{n}=50$ ) exceeded the recommended maximal-minimal limits of weight range (their own weight, which was at the beginning of experiment, by $\pm 1.3 \mathrm{~kg}$ ). For achievement of proper results students had to significantly intensify their everyday motor functioning. Students noted that besides academic physical culture lessons the started to attend additional trainings in sport clubs and circles (in average 2 additional trainings a week) and increased the scope of their everyday motor functioning (morning exercises, morning and evening runs, walking and etc.). Increase of motor functioning significantly influenced on students' physical fitness level. At the end of the research control tests showed certain increment in strength and quickness and confident increase of endurance in experimental group. Correctness of such approach is proved also in other works [44, 47].

Experimental group students noted that they had to significantly expand their knowledge about healthy eating dietology and weight correction. All students mentioned that they regularly read scientific literature on such topics and tried to correct their everyday eating basing on acquired information. Students also noted that their usual eating regime and food significantly changed. The students changed the quantity and time of eating, increasing the quantity of eating periods (up to 5-6 a day). The students reduced calorific capacity and the volume of taken food. They started to drink 1.5-3 liters of purified water everyday, use vitamin complexes. Fulfillment o such simple and feasible recommendations played important role in maintaining optimal body mass. It should be especially noted that in our researches we set minimal admitted threshold of body weight reduction. It is connected with the necessity to prevent from potentially dangerous body mass reduction means (fasting, medications, bio-adds and etc.). Thus, in this research we made an attempt to realize conception of eating culture among youth. Such approach is also proved in other researches $[8,26]$.

\section{Conclusions}

1. Analysis of specialists' scientific works in the field of health protection, medicine, sports and physical education permits to speak about significant worsening of most young people's physical condition and health. The main threats for students' health are: immobile way of life and obesity. Just to elimination of these global threats the works of scientists, dealing with students' health protection, shall be devoted.

2. In opinion of the most of scientists strengthening of students' health shall be facilitated by programs of increasing young people's physical functioning. Unfortunately it is necessary to admit that programs, offered by specialists are quite different. Some of them are rather contradictory and questionable. It was found that instructors of physical culture, medical workers, and coaches offer different approaches to cultivation healthy life style values in students' medium. Sometimes, such programs are rather subjective and inconsistent. Thus, there is high demand in objective programs of high quality for students' physical functioning intensification.

3. Implementation of criterion - optimal body mass indicator - in list of required for passing physical culture test requirements will be rather objective and simple mean of students' motor functioning intensification. In our research it was determined that for successful fulfillment of this condition students had to significantly increase their everyday motor functioning. Therefore, implementation of compulsory control over body mass in practice of students' physical education will facilitate fighting with global threats for young people's health: obesity and immobility.

\section{Conflict of interests}

The author declares that there is no conflict of interests.

\section{References:}

1. Abalkhail B, Shawky S, Ghabrah T. Perception of body weight among Saudi school children. Journal of Family and Community Medicine, 2002; 9(3): 35-49.

2. Adyrkhaev SG. Modern technology of physical education of disabled students in conditions of inclusive education. Pedagogics, psychology, medical-biological problems of physical training and sports, 2016; 20(1): 4-12. doi:10.15561/18189172.2016.0101

3. Al-Isa A, Campbell J, Desapriya E, Wijesinghe N. Social and health factors associated with physical activity among Kuwaiti college students. Journal of Obesity, 2011;5:123130. doi:10.1155/2011/512363

4. Allender S, Cowburn G, Foster Ch. Understanding participation in sport and physical activity among children and adults: a review of qualitative studies. Health Education Research, 2006; 21(6): 826-835. doi:10.1093/her/cyl063

5. Berryman J. Exercise in medicine: A historical perspective. Current Sports Medicine Reports, 2010; 9(4): 1-7.

6. Blair S, Cheng Y, Holder J. Is physical activity or physical fitness more important in defining health benefits? Medicine and Science in Sports and Exercise, 2001; 33(6 Suppl.): S379-99.

7. Bodnar IR, Andres AS. Tests and standards for expresscontrol of physical fitness and health of middle school age pupils. Pedagogics, psychology, medical-biological problems of physical training and sports, 2016; 20(4): 11-16. doi:10.15561/18189172.2016.0402

8. Bodnar IR, Stefanyshyn MV, Petryshyn YV. Assessment of senior pupils' physical fitness considering physical condition 
indicators. Pedagogics, psychology, medical-biological problems of physical training and sports, 2016; 20(6): 9-17. doi:10.15561/18189172.2016.0602

9. Bogdanis G. Effects of physical activity and inactivity on muscle fatigue. Frontiers in Physiology, 2012; 3: 140-142. doi:10.3389/fphys.2012.00142

10.Brettschneider A, Schaffrath R, Wiegand S. Development and validation of correction formulas for self-reported height and weight to estimate BMI in adolescents. Results from the KiGGS study. Obesity Facts, 2015; 8: 30-42. doi:10.1159/000375109

11.Bu S. Correction of eating habits and prevention of weight gain by nutrition education in Korean college students. FASEB Journal [Internet], 2012 [cited 2016 Dec 16]; 26(1). Available from: http://www.fasebj.org/content/26/1_ Supplement/1010.7

12.Cressy J. The Roles of physical activity and health in enhancing student engagement: implications for leadership in post secondary education. College Quarterly [Internet], 2011 [cited 2016 Dec 20]; 14(4). Available from: http:// collegequarterly.ca/2011-vol14-num04-fall/cressy.html

13.D'Abundo M, Sidman C, Fiala K. Sitting behavior and physical activity of college students: Implications for health education and promotion. International Journal of Adult Vocational Education and Technology, 2015; 6(3): 61-78. doi:10.4018/IJAVET.2015070105

14.Daskapan A, Tuzun E, Eker L. Perceived barriers to physical activity in university students. Journal of Sports Science and Medicine, 2006; 5: 615-620.

15.Ellert U, Brettschneider A, Wiegand S, Kurth B. Applying a correction procedure to the prevalence estimates of overweight and obesity in the German part of the HBSC study. BMC Research Notes [Internet], 2014 [cited 2016 Dec 18]; 7: 178-181. doi:10.1186/1756-0500-7-181 Available from: https://bmcresnotes.biomedcentral.com/ articles/10.1186/1756-0500-7-181

16.Fagaras S, Radu L, Vanvu G. The level of physical activity of university students. Procedia - Social and Behavioral Sciences, 2015; 197: 1454-1457. doi:10.1016/j. sbspro.2015.07.094

17.Gaskov AV, Kuzmin VA, Kudryavtsev DM, Iermakov SS. Successfulness of general and special physical qualities' development on different stage of students-boxers' training. Physical Education of Students, 2016;20(1):4-11.

18.Gopinath B, Hardy L, Baur L. et al. Physical activity and sedentary behaviors and healt-related quality of life in adolescents. Pediatrics, 2012; 130(1): 167-174. doi:10.1542/ peds.2011-3637

19.Grygiel-Górniak B, Tomczak A., Krulikowska N. et al. Physical activity, nutrional status, and dietary habits of students of a medical university. Sport Science for Health, 2016; 12: 261-267. doi:10.1007/s11332-016-0285-x

20.Iermakov SS, Arziutov GN, Jagiello W. Quick training of students to judo techniques. Archives of Budo, 2016;12:1524.

21.Iermakov SS, Podrigalo LV, Jagiello W. Hand-grip strength as an indicator for predicting the success in martial arts athletes. Archives of Budo, 2016;12:179-86.

22.Judge L, Bellar D, Lee D. et al. An exploratory study of physical activity patterns of college students at a Midwest State University in the United States. The Sport Journal [Internet], 2012 [cited 2016 Dec 19]. Available from: http:// thesportjournal.org/article/an-exploratory-study-of-physicalactivity-patterns-of-college-students-at-a-midwest-stateuniversity-in-the-united-states/
23.King K, Vidourek R, English L, Merianos A. Vigorous physical activity among college students: using the health belief model to assess involvement and social support. Archives of Exercise in Health in Disease, 2014; 4(2): 267279. doi:10.5628/aehd.v4i2.153

24.Kopeikina EN, Drogomeretsky VV, Kondakov VL, Kovaleva MV, Iermakov SS. Modification of Harvard step-test for assessment of students' with health problems functional potentials. Physical education of students, 2016; 20(4): 4450. doi:10.15561/20755279.2016.0405

25.Kopylov YuA, Jackowska LN, Kudryavtsev MD, Kuzmin VA, Tolstopyatov IA, Iermakov S S. The concept of structure and content of health related trainings for higher educational establishments' students. Physical education of students, 2015; 19(5): 23-30. doi:10.15561/20755279.2015.0504

26.Korn L, Gonen E, Shaked Y, Golan M. Health Perceptions, Self and Body Image, Physical Activity and Nutrition among Undergraduate Students in Israel. PLoS ONE [Internet], 2013 [cited 2016 Dec 22]; 8(3): e58543. doi:10.1371/journal. pone.0058543 Available from: http://journals.plos.org/ plosone/article?id=10.1371/journal.pone. 0058543

27.Kozina ZL, Iermakov SS, Kadutskaya LA, Sobyanin FI, Krzeminski M, Sobko I N, Ryepko OA. Comparative characteristic of correlation between pulse subjective indicators of girl students' and school girls' reaction to physical load. Physical education of students, 2016; 20(4): 24-34. doi:10.15561/20755279.2016.0403

28.Kretschmann Rolf. Comparison of 9th grade students' physical activity levels during recess and regular class periods using objective measurement. Pedagogics, psychology, medical-biological problems of physical training and sports, 2016; 20(4): 59-63. doi:10.15561/18189172.2016.0409

29.Kudryavtsev MD, Kramida IE, Iermakov SS, Osipov AYu. Development dynamic of healthy life style personality component in relatively healthy students. Physical education of students, 2016; 20(6): 26-33. doi:10.15561/20755279.2016.0603

30.Kudryavtsev M, Kramida I, Osipov A. Influence of monitor bad habits on healthy lifestyle of students. Theory and Practice of Physical Culture, 2016; 6: 24-26.

31.Kudryavtsev MD, Kopylov YuA, Kuzmin VA, Ionova OM, Yermakova TS. Personality oriented system of strengthening of students' physical, psychic and social-moral health. Physical education of students, 2016; 20(3): 43-52. doi:10.15561/20755279.2016.0308

32.Kudryavtsev MD, Kramida IE, Iermakov SS. Influence of studying in higher educational establishment on students' harmful computer habits. Physical education of students, 2016; 20(5): 17-23. doi:10.15561/20755279.2016.0503

33.Kudryavtsev MD, Kramida IE, Kuzmin VA, Iermakov SS, Cieslicka Miroslawa, Stankiewicz Blazej. Influence of study in hee on ubiquity and strength of students' computer gambling. Physical education of students, 2016; 20(3): 1322. doi:10.15561/20755279.2016.0302

34.Kuzmin VA, Kopylov YuA, Kudryavtsev MD, Galimov GY, Iermakov S S. Substantiation of effectiveness of trainings on health related methodic for students with weakened motor fitness. Physical education of students, 2015; 19(6): 43-49. doi:10.15561/20755279.2015.0606

35.Osipov A, Gibaeva N, Kachaeva Yu, Pereus O. The method of HOT IRON as a means of increasing the level of physical development of students and formation of their motivation for regular physical exercise. Bulletin of Krasnoyarsk State Pedagogical University named after V.P. Astafiev, 2014; 4(30): 82-86. 
36.Osipov A, Kadomtseva E, Lepilina T. et al. Creating a social sports environment in the universities, with the aim of preserving the health of all participants in the educational process (on the example of the leading universities of Krasnoyarsk region). In the World of Scientific Discoveries, 2015; 3.1(63): 735-748.

37.Osipov A, Kadomtseva E, Lepilina T. et al. The search for effective methods preservation and promotion of health of students in physical education in universities. In the World of Scientific Discoveries, 2015; 3.8(63): 3557-3573.

38.Osipov A, Starova O, Malakhova A. et al. Modernization process of physical education of students in the framework of implementation of the state strategy for the development of physical culture, sport and tourism in the Russian Federation. Journal of Physical Education and Sport, 2016; 4: 12361241. doi:10.7752/jpes.2016.04196

39.Osipov A, Vonog V, Prokhorova O, Zhavner T. Student learning in physical education in Russia (problems and development perspectives). Journal of Physical Education and Sport, 2016; 1(Supplement issue): 688-693. doi:10.7752/ jpes.2016.s1111

40.Osipov AYu, Kudryavtsev MD, Kramida IE, Iermakov SS, Kuzmin VA, Sidorov LK. Modern methodic of power cardio training in students' physical education. Physical education of students, 2016; 20(6): 34-39. doi:10.15561/20755279.2016.0604

41.Peres A, Gabriel K, Nehme E. Measuring the bias, precision, accuracy, and validity of self-reported height and weight in assessing overweight and obesity status among adolescents using a surveillance system. International Journal of Behavioral Nutrition and Physical Activity, 2015; 12(1): S2. doi:10.1186/1479-5868-12-S1-S2

42.Pescatello L, VanHeest J. Physical activity mediates a healthier body weight in the presence of obesity. British Journal of Sports Medicine, 2000; 34(2): 86-93. doi:10.1136/ bjsm.34.2.86

43.Plotnikoff R, Costigan S, Williams R. et al. Effectiveness of interventions targeting physical activity, nutrition and healthy weight for university and college students: a systematic review and meta-analysis. International Journal of Behavioral Nutrition and Physical Activity, 2015; 12: 45. doi:10.1186/s12966-015-0203-7

44.Podrigalo LV, Iermakov SS, Alekseev AF, Rovnaya OA. Studying of interconnectios of morphological functional indicators of students, who practice martial arts. Physical education of students, 2016; 20(1): 64-70. doi:10.15561/20755279.2016.0109

45.Santos E, Tassitano R, do Nascimento W. et al. Body satisfaction and associated factors among high school students. Revista Paulista de Pediatria, 2011; 29(2): 214223.

46.Sattelmair J, Ratey J. Physically active play and cognition: An academic matter? American Journal of Play, 2009; 1(3): 365-374.

47.Skurikhina NV, Kudryavtsev MD, Kuzmin VA, Iermakov S S. Fitness yoga as modern technology of special health groups' girl students' psycho-physical condition and psychosocial health strengthening. Physical education of students, 2016; 20(2): 24-31. doi:10.15561/20755279.2016.0204

48.Solovey E. Comparative analysis of curricula of conventional and sports-centered physical education of students in vocational secondary education. Physical Culture: Upbringing, Education, Workout, 2015; 6: 63-64.

49.Tammelin T. Lack of physical activity and excessive sitting: health hazards for young people? Jornal de Pediatria (Rio de Janeiro), 2009; 85(4): 283-285.

50.ten Hope M. Physical Activity, Motivation, and Depression in College Students (Undergraduate honors thesis, University of Redlands). 2015; 51 p. Retrieved from: http://inspire. redlands.edu/cas_honors/88

51. Warburton D, Nikol C, Bredin S. Health benefits of physical activity: The evidence. Canadian Medical Association Journal, 2006; 174(6): 801-809. doi:10.1503/cmaj.051351

Information about the authors:

Osipov A.Yu.; http://orcid.org/0000-0002-2277-4467; Ale44132272@ya.ru; Siberian Federal University; 79 Svobodny pr., Krasnoyarsk, 660041, Russia.; Professor V.F. Voino-Yasenetsky Krasnoyarsk State Medical University; P. Zeleznyak, 1, Krasnoyarsk, 660022, Russia.

Kudryavtsev M.D.; http://orcid.org/0000-0002-2432-1699; kumid@yandex.ru; Siberian Federal University; 79 Svobodny pr., Krasnoyarsk, 660041, Russia. ; Siberian State Aerospace University; Office A-406, 31, Krasnoyarsky Rabochy Av., 660014, Krasnoyarsk, Russia.; Krasnoyarsk State Pedagogical University of V.P. Astafyev; Ada Lebedeva Street 89, Krasnoyarsk, 660049, Russia.

Gruzinky V.ı.; http://orcid.org/0000-0002-2003-0667; gruzenkinvi51@mail.ru; Siberian Federal University; 79 Svobodny pr., Krasnoyarsk, 660041, Russia.

Kramida I.E.; http://orcid.org/0000-0003-4256-2645; kramidai@mail.ru; Siberian State Aerospace University; Office A-406, 31, Krasnoyarsky Rabochy Av., 660014, Krasnoyarsk, Russia.

lermakov S.S.; http://orcid.org/0000-0002-5039-4517; sportart@gmail.com; Belgorod National Research University; 85 Pobedy Street, Belgorod, 308015, Russia.

Cite this article as: Osipov AYu, Kudryavtsev MD, Gruzinky VI, Kramida IE, Iermakov SS. Means of optimal body mass control and obesity prophylaxis among students. Physical education of students, 2017;1:40-45. doi:10.15561/20755279.2017.0107

The electronic version of this article is the complete one and can be found online at: http://www.sportedu.org.ua/index.php/PES/issue/archive

This is an Open Access article distributed under the terms of the Creative Commons Attribution License, which permits unrestricted use, distribution, and reproduction in any medium, provided the original work is properly cited (http://creativecommons.org/licenses/by/4.0/deed.en).

Received: 19.01 .2017

Accepted: 29.01.2017; Published: 10.02.2017 